\title{
Erosion Resistance and Fertility of Frost-Resistant Ecological Substrate in Alpine Region
}

\author{
Cailing Xue*, Ailinaizaier Ainiwaer*, Jiazhen Gao** and Zhaohui Qin*† \\ * College of Economics and Management, China Three Gorges University, Hubei Yichang, 443002, China \\ ** College of Civil Engineering \& Architecture, China Three Gorges University, Hubei Yichang, 443002, China \\ †Corresponding author: Zhaohui Qin; mw19630910@163.com
}

Nat. Env. \& Poll. Tech.

Website: www.neptjournal.com

Received: 01-12-2020

Revised: 27-01-2021

Accepted: 03-03-2021

Key Words:

The alpine region

Fertility

Aggregate

Slope ecological restoration

Principal coponent analysis

\section{ABSTRACT}

This research was conducted to quantitatively evaluate the application effect of the frost-resistant ecological substrate in the rock slope of the hydropower station. Field sampling and laboratory tests were conducted to determine the erosion resistance and fertility of frost-resistant ecological substrate, and the test results were compared with those of natural soils with similar site conditions. The research conclusions were as follows. Compared with the natural soil, the content of $>0.25 \mathrm{~mm}$ mechanicalstable aggregates, $>0.25 \mathrm{~mm}$ water-stable aggregates, average weight diameter, geometric average diameter, organic matter, available nitrogen, available phosphorus, and available potassium of frostresistant ecological substrate, significantly increased. On the contrary, erodibility factor, percentage aggregate disruption, aggregate degree, and dispersion rate decreased evidently. These results showed that erosion resistance and fertility of the frost-resistant ecological substrate have a better prospect in the engineering application of alpine regions. In addition, the principal component analysis showed that the principal component value of frost-resistant ecological substrate increased by 1.9 times that of natural soil. According to the correlation study, the increase in the amount of $>0.25 \mathrm{~mm}$ macroaggregates and organic matter is the primary reason that ecological substrate has greater stability and fertility than natural soil. In conclusion, the frost-resistant ecological substrate was a suitable soil to create a suitable vegetation growth environment on the surface of rock slope in the alpine region.

\section{INTRODUCTION}

Qinghai-Tibet Plateau has abundant hydropower resources, and the rivers in this region have created favorable conditions for the comprehensive development of hydropower (Yuan et al. 2016). A large number of construction measures disturb the original ecosystem function, resulting in the reduction of natural vegetation ( $\mathrm{Li}$ et al. 2015, Xu et al. 2012). Therefore, the application of slope ecological restoration technology which takes both slope reinforcement and vegetation reconstruction into account is relatively common in Qinghai-Tibet Plateau. At present, the slope ecological restoration techniques (Yang et al. 2015) can be used to build habitats suitable for ecological restoration of vegetation growth in southern areas of China (Cheng et al. 2020, Luo et al. 2016). However, the durability and fertility of ecological substrates will be seriously reduced due to the harsh climatic conditions and frequent freeze-thaw cycles in Alpine Region (Dong et al. 2013, Sharma et al. 2006, Zhang et al. 2017). Therefore, to resist the repeated freeze-thaw damage, a new type of frost-resistant ecological substrate was invented by China Three Gorges University (Zhou et al. 2013), which can create suitable vegetation habitats for the restoration of rock exposed slopes in the alpine region. The frost-resistant ecological substrate is composed of plant soil, cement, organic materials, green additives, silica fume, and palm fiber. The indoor test results show that the frost-resistant ecological substrate has good frost resistance and high fertilizer efficiency, but the actual improvement effect of its application still lacks specific data support.

In recent years, much research has been carried out on the changes in soil erosion resistance and fertility in the alpine region. Zhao et al. (2019) selected water-stable aggregates, geometric average diameter, and erodibility factor to study the effect of freeze-thaw on the erosion resistance of northern soil. Gu et al. (2020) selected several evaluation indexes such as average weight diameter, aggregate disruption, and the aggregate degree to comprehensively discuss the characteristics of black soil aggregates under freeze-thaw. Du et al. (2020) pointed out that the freeze-thaw process has a significant impact on the soil physical structure, chemistry, and vegetation growth of alpine grassland. So optimal conditions and technical measures to reduce soil nutrient loss during the freeze-thaw period should be explored. Change of fertility is not only a key factor reflecting the quality of the soil (Cai et al. 2008), but also can reflect the restoration 
Table 1: Basic properties of planting soil.

\begin{tabular}{|lllllll|}
\hline Planting soil type & Dry density $/\left(\mathrm{g} / \mathrm{cm}^{3}\right)$ & $\mathrm{pH}$ & \multicolumn{4}{ll}{ Particle size distribution $(\%)$} \\
\cline { 3 - 6 } & & & $2-0.5 \mathrm{~mm}$ & $0.5-0.25 \mathrm{~mm}$ & $0.25-0.075 \mathrm{~mm}$ & $<0.075 \mathrm{~mm}$ \\
\hline Fine-grained sand soil & 1.43 & 6.7 & 60.82 & 16.79 & 9.47 \\
\hline
\end{tabular}

effect of slope ecological engineering and vegetation growth status (Rivera et al. 2014, Li et al. 2018).

Many studies have contributed to the understanding and evaluation of soil resistance and fertility. However, most of the research subjects are limited to natural soil, and there are few reports of the durability and fertility changes of ecological substrates on slopes in alpine areas. Therefore, this paper takes a rocky slope in the engineering area of Dagu Hydropower Station as the experimental site, spray seeding this frost-resistant ecological substrate according to past research methodologies. Through outdoor sampling and indoor test, the erosion resistance and fertility index were analyzed and compared with natural soils with similar site conditions. The purpose of this study is to deeply understand the application effect of the frost-resistant ecological substrate in the alpine region and to provide a scientific basis for the practical application of ecological substrate in engineering.

\section{MATERIALS AND METHODS}

Overview of test area: Dagu hydropower station is located in Zengji Township, Sangri County, Shannan City, Tibet Autonomous Region, on the eastern edge of the Qinghai-Tibet Plateau. The control basin area of the hydropower station is $157400 \mathrm{~km}^{2}$ with a length of $49 \mathrm{~km}$ main stem and $282 \mathrm{~m}$ river fall along the Yarlung Tsangpo River. The minimum elevation at the station is $3400 \mathrm{~m}$ above sea level with a gradient of about $5.75 \%$. The valley width here is around 40 200 m, and the maximum elevation on both banks is more than $6000 \mathrm{~m}$. The characteristic of the landform is a typical high mountain and deep valley. The climate in the region is described as plateau temperate monsoon semi-humid, with less rainfall and drought in winter and more rainfall in summer. According to the statistics date from meteorological stations, the annual average temperature, precipitation, evaporation, and relative humidity are $9.2^{\circ} \mathrm{C}, 540.5 \mathrm{~mm}$, $2084.1 \mathrm{~mm}$, and $51 \%$, respectively, and the maximum frozen soil depth over the years is $19 \mathrm{~cm}$. The soil in the project area is mainly composed of grassland soil, aeolian sandy soil, and skeleton soil. Meanwhile, the lithology of the excavated slope is mainly biotite granodiorite with a medium-fine grained structure.

Engineering construction and sampling: A rocky slope in the engineering disturbance area of the Dagu hydropower station was selected for the ecological restoration with the frost-resistant ecological substrate. The construction time of ecological restoration was concentrated from June to July in 2019. The mechanical dry spray method is used to spray the surface of the rock slope. Spraying is divided into two layers: the base layer and the surface layer. The base layer and surface layer were sprayed with $10 \mathrm{~cm}$ and $2 \mathrm{~cm}$ respectively, and the plant seeds were mixed into the surface layer. The plant soil was taken from a natural slope beside the rock slope, and the basic properties of soil are shown in Table 1. The cement is ordinary Portland cement with a strength grade of 32.5, the organic material is made of fir sawdust with a particle size of less than $2 \mathrm{~mm}$, the green additive is a patented product, and silica fume and palm fiber are directly purchased from the local company. The frost-resistant ecological substrate is composed of plant soil, cement, organic material, green additives, silica fume, and palm fiber at a dry weight ratio of 100:10:8:5:3:1 (Zhou et al. 2013). The rocky slope with single spraying of plant soil was selected as the control slope, and the sides of both slopes were facing north, and the slope gradient and height were about $60^{\circ}$ and $3.4 \mathrm{~m}$, respectively.

In July 2020, six plots with good vegetation growth were selected as sampling plots in two kinds of slopes, and the size of a single plot was set to $2 \mathrm{~m} \times 2 \mathrm{~m}$. A five-point sampling method was adopted to collect $5-10 \mathrm{~cm}$ surface soil from each plot, and the weight of each sample was about $2 \mathrm{~kg}$. The specific method is as follows: Five spots are randomly picked according to the $\mathrm{S}$ shape in the depth range of the sample site's soil layer to make a sample, and huge soil blocks are collected when sampling. The soil samples which were packed in plastic boxes were carefully transported to the laboratory, then dried naturally at $25^{\circ} \mathrm{C}$. All samples were stripped into $10-12 \mathrm{~mm}$ small blocks along the natural structure plane after the sample is air-dried to below the plastic limit while removing plant roots and small stones. The properties of each sample were measured three times in the laboratory, and averaging the experimental results.

Index selection and statistical analysis: In this paper, the evaluation indexes of soil aggregate characteristics and fertility are selected as follows.

1. The content of $>0.25 \mathrm{~mm}$ mechanical-stable aggregates $(\%)=>0.25 \mathrm{~mm}$ mechanical-stable aggregate mass/ the sum of mechanical aggregate mass of each particle size. 
2. The content of $>0.25 \mathrm{~mm}$ water-stable aggregates $(\%)$ $=>0.25 \mathrm{~mm}$ water-stable aggregate mass / the sum of water-stable aggregate mass of each particle size.

3. Mean weight diameter (MWD, mm): $M W D=\sum_{\mathrm{i}}^{\mathrm{n}} \overline{X_{\mathrm{i}}} \omega_{\mathrm{i}}$.

4. Geometric mean diameter (GMD, mm): $G M D=\exp \left(\sum_{\mathrm{i}=1}^{\mathrm{n}} \omega_{\mathrm{i}} \ln X_{\mathrm{i}}\right)$
5. Percentage aggregate disruption $(\mathrm{PAD}, \%)=1-$ the content of $>0.25 \mathrm{~mm}$ aggregates after dry sieving/the content of $>0.25 \mathrm{~mm}$ aggregates after wet sieving $\times$ $100 \%$.

6. The soil erodibility factor $\mathrm{K}$ was calculated by EPIC equation:

$$
K=\left\{0.2+0.3 \exp \left[-0.0256 S_{\mathrm{a}}\left(1-\frac{S_{\mathrm{i}}}{100}\right)\right]\right\}\left[\frac{S_{\mathrm{i}}}{C_{1}+S_{\mathrm{i}}}\right]^{0.3} \times\left[1-\frac{0.25 C}{C+\exp (3.72-2.95 C)}\right] \times\left[1-\frac{0.7 S_{\mathrm{n}}}{S_{\mathrm{n}}+\exp \left(-5.51+22.9 S_{\mathrm{n}}\right)}\right]
$$

Where, $\mathrm{S}_{\mathrm{a}}$ is the content of sand $(2 \sim 0.05 \mathrm{~mm}, \%)$; $\mathrm{S}_{\mathrm{i}}$ is the content of silt $(0.05 \sim 0.002 \mathrm{~mm} \%) ; \mathrm{C}_{1}$ is the content of clay $(<0.002 \mathrm{~mm}, \%)$; $\mathrm{C}$ is the content of organic carbon $(\%) ; \mathrm{S}_{\mathrm{n}}$ is $1-\mathrm{S}_{\mathrm{a}} / 100 . K$ is the international system unit (t hm2 H / (hm2 MJ mm).

7. Aggregate degree $(\%)=>0.05 \mathrm{~mm}$ micro-aggregate analysis value - $>0.05 \mathrm{~mm}$ soil mechanical composition analysis value / $>0.05 \mathrm{~mm}$ micro-aggregate analysis value $\times 100 \%$.

8. Dispersion rate $(\%)=<0.05 \mathrm{~mm}$ micro-aggregate analysis value $/<0.05 \mathrm{~mm}$ mechanical composition analysis value $\times 100 \%$.

9. The indexes of soil fertility: the content of organic matter, available nitrogen, available phosphorus, and available potassium.

Test methods: The particle size distribution of mechanicalstable aggregates was determined by the dry sieving method. The water-stable aggregates particle size distribution is determined by Yoder wet sieving method. According to the mass percentage of the soil particle distribution of each particle size after the dry screening, $50 \mathrm{~g}$ of air-dried soil sample was prepared. Then it was placed in the top layer of the set sieve, water was added, and the sieve was artificially vibrated for 10 minutes, after which the sieve residue was dried and weighed. Organic matter was determined by potassium dichromate-external heating method, available nitrogen was determined by alkali hydrolysis diffusion method, available phosphorus was determined by sodium hydroxide alkali solution-molybdenum blue colorimetric method, available potassium was determined by ammonium acetate extraction-atomic absorption method, and soil microaggregate and mechanical composition were determined by pipette method.

All date statistical analysis was performed using Excel 2019. SPSS 22.0 was used for one-way ANOVA ( $\mathrm{P}<0.05)$, Pearson correlation analysis, and principal component analysis.

\section{RESULTS AND DISCUSSION}

\section{Particle size distribution of mechanical-stable aggregates:} The particle size distribution of mechanical-stable aggregates of the frost-resistant ecological substrate and the natural soil is shown in Fig. 1. Overall, the distribution of the two kinds of soils is relatively similar. Both soils have the highest content of $>7 \mathrm{~mm}$ aggregates. Then the content of $7 \sim 5 \mathrm{~mm}$ and $<0.25 \mathrm{~mm}$ aggregates is second. The aggregates content of $5 \sim 3 \mathrm{~mm}, 3 \sim 2 \mathrm{~mm}, 2 \sim 1 \mathrm{~mm}, 1 \sim 0.5 \mathrm{~mm}, 0.5 \sim 0.25$ $\mathrm{mm}$ have no significant difference, and the content of $3 \sim 2$ $\mathrm{mm}$ aggregates is the least. But there is a certain difference between the frost-resistant ecological substrate and the natural soil. Among them, the content of $>7 \mathrm{~mm}$ aggregates in natural soil is less than that of the frost-resistant ecological substrate, and the content of $<0.25 \mathrm{~mm}$ aggregates in natural soil is about $8.2 \%$ higher than that of the frost-resistant ecological substrate. So, the main difference between both soils is that the content of mechanical macro-aggregates of the frost-resistant ecological substrate is significantly increased, while the content of micro-aggregates is significantly reduced.

Particle size distribution of water-stable aggregates: As shown in Fig. 2, the content of $>5 \mathrm{~mm}$ and $<0.25 \mathrm{~mm}$ waterstable aggregates in frost-resistant ecological substrate are significantly higher than the content of aggregates of $5 \sim 3$ $\mathrm{mm}, 3 \sim 2 \mathrm{~mm}, 2 \sim 1 \mathrm{~mm}, 1 \sim 0.5 \mathrm{~mm}$, and $0.5 \sim 0.25 \mathrm{~mm}$. The content of these five aggregates is all below $6 \%$, and there is no significant difference among them. In comparison, the content of $<0.25 \mathrm{~mm}$ water-stable aggregates in natural soil was the highest, which is significantly higher than that of the frost-resistant ecological substrate. The content of $>5 \mathrm{~mm}$ aggregates in natural soil is only $16.6 \%$, and it is significantly lower than the frost-resistant ecological substrate $(\mathrm{P}<0.05)$. In terms of the content of $5 \sim 3 \mathrm{~mm}, 3$ $\sim 2 \mathrm{~mm}, 2 \sim 1 \mathrm{~mm}, 1 \sim 0.5 \mathrm{~mm}, 0.5 \sim 0.25 \mathrm{~mm}$ aggregates, the difference between both soils are not significant. The results show that the content of $>5 \mathrm{~mm}$ water-stable aggregates of the frost-resistant ecological substrate is significantly higher than that of natural soil, while the 


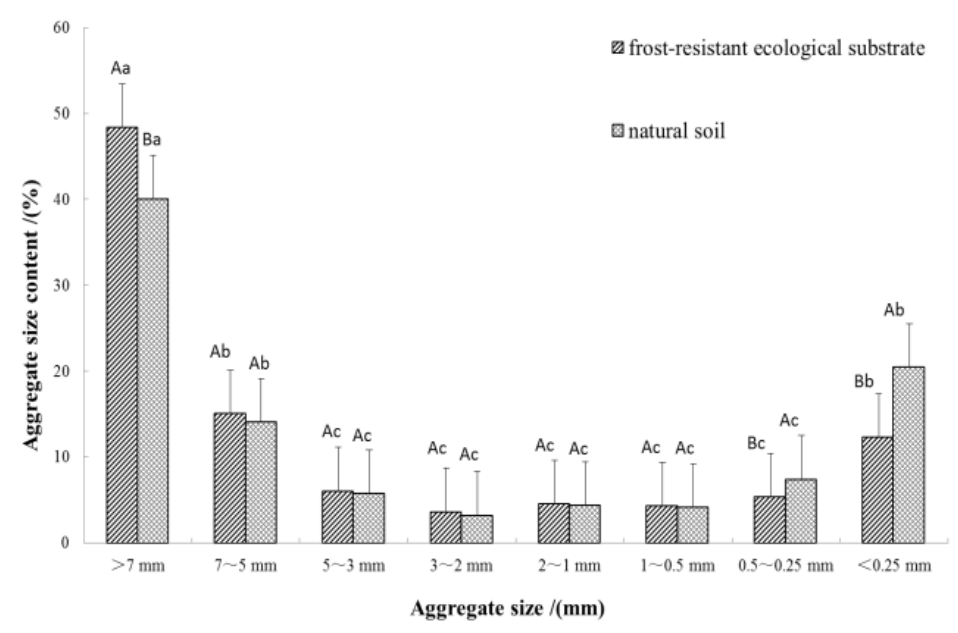

Fig. 1: Particle size distribution of mechanical-stable aggregates.

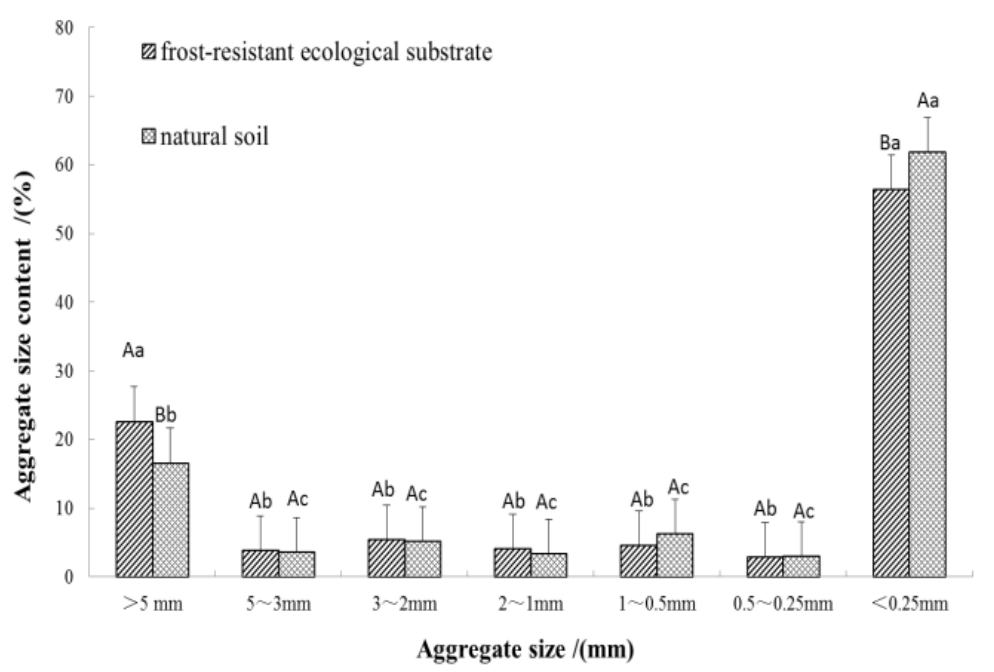

Fig. 2: Particle size distribution of water-stable aggregates.

content of $<0.25 \mathrm{~mm}$ water-stable aggregates is significantly the particle size distribution of aggregates, the content of reduced. $>0.25 \mathrm{~mm}$ mechanical-stable and water-stable aggregates Indexes of erosion resistance and fertility: In terms of in the frost-resistant ecological substrate are $10.4 \%$ and Table 2: Erosion resistance and fertility of both soils.

\begin{tabular}{|c|c|c|c|c|c|c|c|c|c|c|c|c|}
\hline \multirow[t]{2}{*}{ Soil type } & \multicolumn{2}{|c|}{ Aggregate content $(\%)$} & \multirow{2}{*}{$\begin{array}{l}M W D \\
(\mathrm{~mm})\end{array}$} & \multirow{2}{*}{$\begin{array}{l}\text { GMD } \\
(\mathrm{mm})\end{array}$} & \multirow[t]{2}{*}{$P A D(\%)$} & \multirow{2}{*}{$\begin{array}{l}K \\
\left(\mathrm{t} \mathrm{hm}^{2} \mathrm{~h} /\right. \\
\mathrm{hm}^{2} \mathrm{MJ} \\
\mathrm{mm})\end{array}$} & \multirow{2}{*}{$\begin{array}{l}\text { Aggre- } \\
\text { gation } \\
\text { degree } \\
(\%)\end{array}$} & \multirow{2}{*}{$\begin{array}{l}\text { Dis- } \\
\text { persion } \\
\text { rate } \\
(\%)\end{array}$} & \multirow{2}{*}{$\begin{array}{l}\text { Or- } \\
\text { ganic } \\
\text { matter } \\
\left(\mathrm{g} \mathrm{kg}^{-1}\right)\end{array}$} & \multirow{2}{*}{$\begin{array}{l}\text { Available } \\
\text { nitrogen } \\
\left(\mathrm{g} \mathrm{kg}^{-1}\right)\end{array}$} & \multirow{2}{*}{$\begin{array}{l}\text { Available } \\
\text { phospho- } \\
\text { rus } \\
\left(\mathrm{g} \mathrm{kg}^{-1}\right)\end{array}$} & \multirow{2}{*}{$\begin{array}{l}\text { Available } \\
\text { potassium } \\
\left(\mathrm{g} \mathrm{kg}^{-1}\right)\end{array}$} \\
\hline & $\begin{array}{l}\text { Mechani- } \\
\text { cal stable }\end{array}$ & $\begin{array}{l}\text { Water } \\
\text { stable }\end{array}$ & & & & & & & & & & \\
\hline Substrate & $87.72 \mathrm{a}$ & $43.61 \mathrm{a}$ & $2.17 \mathrm{a}$ & $0.53 \mathrm{a}$ & $50.12 \mathrm{a}$ & $0.014 b$ & $29.47 \mathrm{a}$ & $57.48 \mathrm{~b}$ & $22.46 \mathrm{a}$ & $0.183 \mathrm{a}$ & $0.082 \mathrm{a}$ & $0.127 \mathrm{a}$ \\
\hline $\begin{array}{l}\text { Natural } \\
\text { soil }\end{array}$ & $79.49 b$ & $38.22 \mathrm{~b}$ & $1.71 \mathrm{~b}$ & $0.41 \mathrm{~b}$ & $52.51 \mathrm{a}$ & $0.022 \mathrm{a}$ & $21.24 \mathrm{~b}$ & $71.63 \mathrm{a}$ & $14.27 \mathrm{~b}$ & $0.142 \mathrm{~b}$ & $0.064 \mathrm{~b}$ & $0.095 \mathrm{~b}$ \\
\hline $\begin{array}{l}\text { Relative } \\
\text { change } \\
\text { rate }\end{array}$ & $10.4 \%$ & $14.1 \%$ & $26.9 \%$ & $29.3 \%$ & $-4.0 \% \% \%$ & $-36.4 \%$ & $38.7 \%$ & $-19.8 \%$ & $57.4 \%$ & $28.9 \%$ & $28.1 \%$ & $33.7 \%$ \\
\hline
\end{tabular}


Table 3: Correlation between different indexes.

\begin{tabular}{|llllllllllll|}
\hline & $X_{1}$ & $X_{2}$ & $X_{3}$ & $X_{4}$ & $X_{5}$ & $X_{6}$ & $X_{7}$ & $X_{8}$ & $X_{9}$ & $X_{10}$ & $X_{11}$ \\
\hline$X_{1}$ & 1.000 & & & & & & & & & & \\
$X_{2}$ & 0.157 & 1.000 & & & & & & & & & \\
$X_{3}$ & 0.413 & $0.850^{*}$ & 1.000 & & & & & & & & \\
$X_{4}$ & 0.298 & $0.959^{* *}$ & $0.961^{* *}$ & 1.000 & & & & & & & \\
$X_{5}$ & 0.361 & $-0.863^{*}$ & -0.605 & -0.761 & 1.000 & & & & & & \\
$X_{6}$ & -0.307 & $-0.975^{* *}$ & $-0.942^{* *}$ & $-0.996^{* *}$ & 0.769 & 1.000 & & & & & \\
$X_{7}$ & $-0.871^{*}$ & 0.080 & -0.036 & 0.007 & -0.531 & 0.009 & 1.000 & & & & \\
$X_{8}$ & $-0.818^{*}$ & -0.032 & -0.066 & -0.064 & -0.407 & 0.087 & $0.975^{* *}$ & 1.000 & & & \\
$X_{9}$ & -0.454 & 0.390 & 0.443 & 0.441 & -0.634 & -0.405 & 0.729 & 0.779 & 1.000 & & \\
$X_{10}$ & -0.408 & 0.366 & 0.471 & 0.444 & -0.589 & -0.401 & 0.701 & 0.761 & $0.995^{* *}$ & 1.000 & \\
$X_{11}$ & -0.443 & 0.313 & 0.375 & 0.360 & -0.557 & -0.332 & 0.735 & 0.807 & $0.986^{* *}$ & $0.918^{* *}$ & 1.000 \\
$X_{12}$ & -0.474 & 0.371 & 0.409 & 0.406 & -0.625 & -0.379 & 0.773 & $0.824^{*}$ & $0.990^{* *}$ & $0.879^{*}$ & $0.885^{*}$ \\
\end{tabular}

Note: ** is extremely significant correlation at 0.01 level; * is significant correlation at 0.05 level. $\mathrm{X}_{1}$ is the content of mechanical-stable aggregates (\%); $\mathrm{X}_{2}$ is the content of water-stable aggregates $>0.25 \mathrm{~mm} ; \mathrm{X}_{3}$ is the average weight diameter (MWD, mm); $\mathrm{X} 4$ is the geometric average diameter (GWD, $\mathrm{mm}) ; \mathrm{X}_{5}$ is the percentage aggregate disruption ( $\left.\mathrm{PAD}, \%\right) ; \mathrm{X}_{6}$ is the erodibility factor $\mathrm{K}(\mathrm{t} \mathrm{hm} 2 \mathrm{H} / \mathrm{hm} 2 \mathrm{MJ} \mathrm{mm}) ; \mathrm{X}_{7}$ is the aggregate degree $(\%) ; \mathrm{X}_{8}$ is the dispersion rate $(\%) ; \mathrm{X}_{9}$ is the content of organic matter $\left(\mathrm{g} \mathrm{kg}^{-1}\right) ; \mathrm{X}_{10}$ is the content of available nitrogen $\left(\mathrm{g} \mathrm{kg}^{-1}\right), \mathrm{X}_{11}$ was the content of available phosphorus $\left(\mathrm{g} \mathrm{kg}^{-1}\right)$, and $\mathrm{X}_{12}$ was the content of available potassium $\left(\mathrm{g} \mathrm{kg}^{-1}\right)$. The following is the same.

Table 4: PCA analysis of index.

\begin{tabular}{|lllllllllllllllll}
\hline $\begin{array}{l}\text { Principal } \\
\text { component }\end{array}$ & \multicolumn{2}{l}{ Factor load of each index } & $X_{1}$ & $X_{2}$ & $X_{3}$ & $X_{4}$ & $X_{5}$ & $X_{6}$ & $X_{7}$ & $X_{8}$ & $X_{9}$ & $X_{10}$ & $X_{11}$ & $X_{12}$ & $\begin{array}{l}\text { Characteris- } \\
\text { tic root }\end{array}$ & $\begin{array}{l}\text { Cumulative } \\
\text { contribution } \\
\text { rate }(\%)\end{array}$ \\
\hline$Y_{1}$ & -0.409 & 0.638 & 0.607 & 0.646 & -0.835 & -0.624 & 0.717 & 0.704 & 0.944 & 0.929 & 0.909 & 0.942 & 6.925 & 57.71 \\
$Y_{2}$ & -0.772 & -0.709 & -0.746 & -0.760 & 0.267 & 0.775 & 0.621 & 0.688 & 0.208 & 0.193 & 0.273 & 0.249 & 3.981 & 90.89 \\
\hline
\end{tabular}

$14.1 \%$ higher than those of natural soil, respectively. The MWD and GMD of a frost-resistant ecological substrate are $26.9 \%$ and $29.3 \%$ higher than those of natural soil, respectively. The percentage aggregate disruption PAD and erodibility factor $\mathrm{K}$ are $4 \%$ and $36.4 \%$ lower than those of natural soil, respectively. These results indicate that the aggregate structure and anti-dispersion ability of frostresistant ecological substrate has improved. In the aspect of fertility, the organic matter content of the frost-resistant ecological substrate is $57.4 \%$ higher than that of the natural soil. Meanwhile, the content of available nitrogen, available phosphorus, and available potassium are $28.9 \%, 28.1 \%$, and $33.7 \%$ higher than those of the natural soil, respectively. It also shows that frost-resistant ecological substrate is more conducive to the growth of plants.

Correlation analysis of indexes: Correlation analysis of the twelve evaluation indexes mentioned above in this article is conducted, and the results are shown in Table 3. The results show that the content of $>0.25 \mathrm{~mm}$ water-stable aggregates $\mathrm{R}_{0.25}\left(\mathrm{X}_{2}\right)$ and organic matter content $\left(\mathrm{X}_{9}\right)$ of the frost-resistant ecological substrate is closely related to other indexes. For example, the water-stable aggregates content
$\mathrm{R}_{0.25}\left(\mathrm{X}_{2}\right)$ is significantly and positively correlated with $\operatorname{MWD}\left(\mathrm{X}_{3}\right)$ and GWD $\left(\mathrm{X}_{4}\right)$. The organic matter content $\left(\mathrm{X}_{9}\right)$ significantly and positively correlated with available nitrogen $\left(\mathrm{X}_{10}\right)$, available phosphorus $\left(\mathrm{X}_{11}\right)$, and available potassium $\left(\mathrm{X}_{12}\right)$. Therefore, the content of $>0.25 \mathrm{~mm}$ water-stable aggregates $\mathrm{R}_{0.25}\left(\mathrm{X}_{2}\right)$ and organic matter content $\left(\mathrm{X}_{9}\right)$ are the most important indexes affecting the erosion resistance and fertility of the frost-resistant ecological substrate, respectively.

The principal component analysis: The SPSS software is used to conduct principal component analysis on the twelve indexes, and the results are shown in Table 4. According to the results, the above-mentioned twelve indexes can extract two principal components, and the two eigenvalues are 6.925 and 3.971 respectively. The contribution rate of principal component $Y_{1}$ and principal component $Y_{2}$ are $57.71 \%$ and $33.18 \%$, respectively. The cumulative contribution rate of both components can reach $90.89 \%$, which meets the requirements of principal component analysis for information coverage.

It can be seen from a load of each index in Table 4 that the nutrient contents of organic matter $\left(X_{9}\right)$, available nitrogen 
Table 5: Main component values of both soils.

\begin{tabular}{|llll|}
\hline Soil type & First principal component $Y_{1}$ & Second principal component $Y_{2}$ & Comprehensive principal component $Y$ \\
\hline Frost-resistant ecological substrate & 2.557 & -0.220 & 1.543 \\
Natural soil & 0.544 & -0.850 & 0.532 \\
\hline
\end{tabular}

$\left(X_{10}\right)$, available phosphorus $\left(X_{11}\right)$, and available potassium $\left(X_{12}\right)$ contribute greatly to the main component $Y_{1}$. For the main component $Y_{2}$, the major contributions are the content of $>0.25 \mathrm{~mm}$ mechanical-stable aggregates $\left(X_{1}\right)$, the content of $>0.25 \mathrm{~mm}$ water-stable aggregates R0.25 $\left(X_{2}\right)$, mean weight diameter $M W D\left(X_{3}\right)$, and geometric mean diameter $G W D\left(X_{4}\right)$.

From the principal component loads and characteristic roots in Table 4, the first and second principal component expressions can be obtained respectively as follows.

$Y_{1}=-0.155 X_{1}+0.242 X_{2}+0.231 X_{3}+0.245 X_{4}-0.317 X_{5}$ $-0.237 X_{6}+0.272 X_{7}+0.268 X_{8}+0.359 X_{9}+0.353 X_{10}$ $+0.345 X_{11}+0.358 X_{12}$

$Y_{2}=-0.387 X_{1}-0.355 X_{2}-0.374 X_{3}-0.381 X_{4}+0.134 X_{5}$ $+0.388 X_{6}+0.311 X_{7}+0.345 X_{8}+0.104 X_{9}+0.097 X_{10}$ $+0.137 X_{11}+0.125 X_{12}$

In conclusion, the principal component values of the frost-resistant ecological substrate and natural soil are calculated as shown in Table 5 .

According to the proportion of the corresponding characteristic value of each principal component in the total characteristic value of the extracted principal component as the weight, the comprehensive principal component model $Y=0.635 Y_{1}+0.365 Y_{2}$ was obtained, and the comprehensive principal component value of frost-resistant ecological substrate and natural soil was calculated. It can be seen from Table 5 that the comprehensive principal component value of the frost-resistant ecological substrate is 2.9 times that of the natural soil.

\section{DISCUSSION}

In this paper, the application of two kinds of soils in the alpine region shows that the erosion resistance and fertility of frost-resistant ecological substrate are significantly higher than that of natural soil. The main reason is that organic material, green additive, cement, silica fume, and palm fiber are added into the frost-resistant ecological substrate. In terms of soil fertility, organic sawdust mixed in the soil would be transformed into organic matter after decay, which will cause the content of organic matter in the frost-resistant ecological substrate to be higher than that in natural soil. The abundant microbial agents contained in the green additives can also promote the growth of various microorganisms and nutrients in the soil, so soil fertility can be significantly improved in alpine regions. Some studies (Xu et al. 2017, Xie et al. 2019) have shown that the improvement of soil fertility can promote the growth of plants, and the plant roots produced also can increase the soil mechanical properties, which can improve the effect of slope restoration in alpine regions for a long time.

In terms of soil erosion resistance, many scholars (Wang et al. 201, Zhang et al. 2019) have shown that the higher the content of macro-aggregate in soil, the smaller the aggregate dispersion rate, the stronger the soil erosion resistance. One of the reasons is that the hydration reaction of cement generates a large number of gelatin and crystal compounds. These compounds can agglomerate the micro-aggregates to form a crystal network and a solid and dense structure (Zhang et al. 2015), thus increasing the content of macro-aggregates $\left(X_{1}\right)$ and aggregate degree $\left(X_{7}\right)$ in soil, reducing the percentage aggregate disruption $\left(X_{5}\right)$. This result is consistent with Tang's research conclusion (Gao et al. 2020). Second, the addition of silica fume can increase the porosity of the soil, thereby reducing the negative impact of frost heaving and thawing settlement on soil structure and increasing the stability of soil in the alpine region (Liu et al. 2013). The addition of palm fiber can increase the connectivity between soil particles and improve the soil's mechanical properties (Zhang et al. 2018). In addition, studies have shown that the increase of organic matter content is also conducive to the formation of macro-aggregates and the enhancement of soil erosion resistance (Wagner et al. 2007, Yao et al. 2009). Because the organic colloid contained in the organic matter has the function of cementation and agglomeration ( $Y$ ao et al. 2009), it increases the content of macro-aggregates $\left(X_{1}, X_{2}\right)$ and enhances the cohesive force of soil particles. Meanwhile, the organic matter could be decomposed into organic acids under the action of microorganisms, which can prevent the dispersion of aggregates $\left(X_{8}\right)$.

This study also found that the content of water-stable aggregate $R_{0.25}\left(X_{2}\right)$ and organic matter content $\left(X_{9}\right)$ could best reflect the erosion resistance and fertility of frost-resistant ecological substrate respectively because the correlation between the two indexes and other indicators were very high. Zhang et al. (2019) considered that there was a significant correlation between the above two indicators and MWD, GMD, nutrient indicators, which is basically consistent with 
the research results in this paper. The principal component analysis also showed that the contribution rate of water-stable aggregate $R_{0.25}\left(X_{2}\right)$ and organic matter content $\left(X_{9}\right)$ to the frost-resistant ecological substrate was higher. Therefore, the above two indicators can be used to evaluate the erosion resistance and fertility of the frost-resistant ecological substrate in future research.

\section{CONCLUSION}

In terms of aggregate particle size distribution, the frostresistant ecological substrate's content of $>0.25 \mathrm{~mm}$ mechanical-stable aggregates and water-stable aggregates has increased significantly compared to natural soil, which is reflected in improved erosion resistance compared to natural soil. In terms of fertility, the organic matter content, available nitrogen, available phosphorus, and available potassium of frost-resistant ecological substrate increased significantly compared with the natural soil, which was more suitable for plant growth. The principal component analysis showed that the comprehensive principal component value of frostresistant ecological substrate is $190 \%$ higher than that of the natural soil. Therefore, the erosion resistance and fertility of the frost-resistant ecological substrate are significantly higher than those of the natural soil, so this substrate has a better prospect in the engineering application of alpine regions.

\section{ACKNOWLEDGEMENTS}

This study was supported by the Research Fund for Excellent Dissertation of China Three Gorges University (Grant No. 2019BSPY007).

\section{REFERENCES}

Cai, X.B., Zhang, Y.Q. and Shao, W. 2008. Characteristics of soil fertility in alpine steppes at different degradation grades. Acta Ecol. Sin., 3: 1034-1044.

Cheng, H., Xu, W.N., Luo, T., Xia, L., Xiang, H.Y., Ma, P.F. and Xia, D. 2020. Microbial functional diversity as affected by different engineered eco-restoration methods at Xiangjiaba hydropower station. J. Environ. Eng., 146(3): 56-98.

Dong, K., Li, S.W., Kang W.L., Long, H.Z. and Liu, G.X. 2013. Study of the changes in microbe amount and its effect factors in the soils along the Qinghai-Tibet highway. J. Glaciol. Geocryol., 35(2): 457-464.

Du, Z.Y. 2020. Effects of Freeze-thaw Action on Soil Physicochemical and Biological Properties in the Alpine Grasslands. Ecology and Environmental Sciences, 29(5): 1054-1061.

Gao, J.Z., Zhou, M.T., Xu, W.N., Liu, D.X., Shen, J., Peng, S. and Du, Y. 2020. The evolution of structural properties of vegetation concrete under freeze-thaw cycles. Int. J. Electr. Eng. Educ., 5(1): 1-19.

Gu, W.M., Zhou, J.X., Wang, B. and Guan, Y.H. 2020. Effects of the freezethaw cycle on the characteristics of black soil water-stable aggregates. Sci. Soil Water Conserv., 18(4): 45-52.

Li, R.R., Kan, S.S., Zhu, M.K., Chen, J., Ai, X.Y., Chen, Z.Q., Zhang, J.J. and Ai, Y.W. 2018. Effect of different vegetation restoration types on fundamental parameters, structural characteristics, and the soil quality index of artificial soil. Soil Till. Res., 184: 11-23.

Li, Z.W., Wang, Z.Y., Yu, G.A., Wang, X.Z. and Zhang, C.D. 2015. Effects on slope stability of the Yarlung Tsangbu grand canyon under future hydropower development. Mountain Res., 3: 331-338.

Liu, D.X., Xu, W.N., Cheng, Z.L., Zhou, Z.Z., Cai, X.Y. and Zhao, B.Q. 2013. Improvement test on frost resistance of vegetation-concrete and engineering application of test fruitage. Environ. Earth Sci., 69(1):161-170.

Luo, A.D., Yan, Z.L. and Zhai, W.G. 2016. Initial Analysis on the Improvement of Highway Slop Landscape Based on the Ecological Protection. International Conference on Sustainable Energy and Environmental Engineering, 18-19 December 2016, Xiamen, China, DEStech Publications, Inc., Pennsylvania, pp. 31-37

Rivera, D., Mejías, V., Jáuregui, B.M., Costa-Tenorio, M., Lo’́pez-Archilla, A.I., Peco, B. and Singer, A.C. 2014. Spreading topsoil encourages ecological restoration on embankments: Soil fertility, microbial activity, and vegetation cover. PLOS One, 9(7): e101413.

Sharma, S., Szele, Z., Schilling, R., Munch, J.C. and Schloter, M.J. 2006. Influence of freeze-thaw stress on the structure and function of microbial communities and denitrifying populations in soil. Appl. Environ. Microbiol., 72(3): 2148-2154.

Wagner, S., Cattle, S.R. and Scholten, T. 2007. Soil-aggregate formation as influenced by clay content and organic-matter amendment. J. Plant Nutri. Soil Sci., 170(1): 173-180.

Wang, H., Zhang, G.H., Li, N.N., Zhang, B.J. and Yang, H.Y. 2019. Variation in soil erodibility under five typical land uses in a small watershed on the Loess Plateau, China. Catena, 174(3): 24-35.

Xie, X.J. and Zhang, B. 2019. Comprehensive Evaluation on Recovery of Soil Anti-erodibility by Revetment Vegetation Based on Coupling Relationship Analysis. Soils, 51(3): 609-616.

$\mathrm{Xu}$, S.J., Lei, S.T. and Zeng, B. 2017. Stability of root-fixed soil on 4 different slopes in the Three Gorges Reservoir region. Res. Soil Water Conserv., 24(2): 119-123+131.

Xu, W.N., Xia, Z.Y., Zhou, M.T., Liu, D.X. and Xia, D. 2012. Theory and practice of environmental protection technology of vegetation concrete. China Water Power Press, 45: 55-64.

Yang, Y., Yang, J.Y., Zhao, P., Shi, C.Q., Xu, Z.N. and Zhou, F. 2015. Two technologies of concrete frame ecological slope protection and application effect: Taking the Anhui Yuewu highway as an example. Sci. Soil Water Conserv., 13(5): 118-124.

Yao, S.H., Qin, J.T., Peng, X.H. and Zhang, B. 2009. The effects of vegetation on the restoration of the physical stability of severely degraded soil in China. Ecol. Eng., 35(5): 723-734.

Yuan, J.X., Yi, Z.J. and Wang, S.Y. 2016. Geological challenges in the construction of hydropower projects in Qinghai-Tibet plateau and its surrounding areas. Journal of Engineering Geology. J.Eng. Geol., 24(5): 847-855.

Zhang, B.H., Liu, D.X. Xu, Y.K. Huang, B. Ding, Yu. and Xu, W.N. 2018. Single polypropylene fiber determines critical fiber reinforcement length and analysis of pullout characteristics for fiber-reinforced soil vegetation-growing concrete. Bull. Chinese Ceram. Soc., 37(9): 2954-2960+2966.

Zhang, B.J., Zhang, G.H., Yang, H.Y. and Zhu, P.Z. 2019. Temporal variation in soil erosion resistance of steep slopes restored with different vegetation communities on the Chinese Loess Plateau. Catena, 182: 104170

Zhang, H.Y., Wang, K.Q. and Song, Y.L. 2019. soil erosion resistance under different land-use types in the Jianshan river watershed in middle Yunnan Province. J. Soil Water Conserv., 33(5): 50-57.

Zhang, L.Y., Liu, D.X., Xu, W.N. and Tong, B. 2017. A study on the change of three functional microorganism quantities in habitat substrate under freezing-thawing cycles. J. Glaciol. Geocryol., 39(05): 1122-1129. 
Zhang, Q.Q., Wang, J.D., Liu, B.R. and Zeng, Y.J. 2015. Quantitative research on microstructure of modified soil with cement. Hydrogeol. Eng. Geol., 42(3): 92-96.

Zhao, H.C., Wei, X., He, Y. Yu, W.Z. and Wang, T. 2019. Effects of freeze-thaw on soil aggregate characteristics and erodibility factor $\mathrm{K}$.
Res. Soil Water Conserv., 26(5):1-6+13.

Zhou, M.T., Xu, W.N., Hu, H. Hu, X.D., Wu, S.G. and Zhang, S.D. 2013. A Kind of Frost-Resistant Ecological Substrate is Applied in Slope. State Intellectual Property Office of the People's Republic of China. 